\title{
Phagocytosis of Legionella pneumophila
}

\author{
M. A. HALABLAB, L. RICHARDS and M. J. BAZIN
}

\begin{abstract}
Microbial Physiology Research Group, Division of Biosphere Sciences, King's College London, Campden Hill Road, London W8 7AH
\end{abstract}

\section{Introduction}

Metschnikoff, ${ }^{1}$ in 1884 , formulated the theory of phagocytosis and proposed that phagocytes were the first line of defence against invading and potentially pathogenic micro-organisms. It is now known that phagocytosis is one of the most important defence mechanisms against microbial infection in all phyla of the animal kingdom. ${ }^{2}$ The importance of phagocytosis with regard to Legionnaires' disease is related to the ability of the causative organism to resist the bactericidal activity of vertebrate phagocytes and its tendency to survive at high concentrations in the food vacuoles of aquatic amoebae and, possibly, other protozoa and invertebrates. The latter property may result, via protozoal encystment and distribution, in the dispersal of what are, effectively, packets of legionellae to the environment, a phenomenon that may be of significance in the epidemiology of Legionnaires' disease. In addition to Legionnaires' disease, Legionella pneumophila has also been incriminated in an acute febrile non-pneumonic illness referred to as Pontiac fever. ${ }^{3}$ In such cases, it is possible that free-living amoebae reduce the number of viable bacterial cells below the level required to cause acute infection by inhalation. ${ }^{4}$ In this review we consider both phagocytosis of Legionella by phagocytes of the animal defence system and their ingestion by actively feeding protozoa.

\section{Pathogenicity of $L$. pneumophila for different hosts}

L. pneumophila is a facultative intracellular parasite that multiplies in human phagocytes and extracellularly on complex media. ${ }^{5}$ In lung specimens from patients with Legionnaires' disease, clusters of bacteria have been demonstrated in alveolar macrophages. ${ }^{6,7}$ Similar findings have been reported in material from the lungs of guineapigs infected intraperitoneally with $L$. pneumo-

Revised version received 5 Feb. 1990; accepted 31 March 1990. phila. ${ }^{8}$ However, from these observations, it can not be determined whether the bacteria multiplied intracellularly or were phagocytosed after extracellular multiplication. In studies of the interaction between $L$. pneumophila and normal cynomolgus monkey alveolar macrophages, ${ }^{9}$ the latter were found to contain 1-3 bacteria per cell after a 3-h period of interaction. After $24 \mathrm{~h}$, many macrophages contained distended vacuoles filled with legionellae. Furthermore, the multiplication of the bacteria was so rapid and extensive that the entire cytoplasmic compartment of some cells became filled with vesicles containing bacteria. Ultimately the phagocytes were destroyed.

Pulmonary alveolar macrophages are the first line of defence against organisms invading the lungs. These are followed by polymorphonuclear neutrophil leucocytes (PMNL) ${ }^{10,11} \mathrm{~A}$ human macrophage-like cell line (U937), derived from a human histiocytic lymphoma cell line which supported the growth of $L$. pneumophila, has been described. ${ }^{12}$ These cells are phenotypically similar to macrophages, are actively phagocytic and have receptors for IgG and complement subcomponent $C_{3}$. This cell line has been used for testing $L$. pneumophila strains containing a gene encoding for optimal intracellular infection that has been cloned and sequenced. ${ }^{13,14}$ In addition to the U937 cell line, investigators have employed a variety of host cells capable of supporting growth of L. pneumophila, including human monocytes, ${ }^{5}$ free-living protozoa, ${ }^{15-20}$ human and animal epithelial cell lines, ${ }^{21,22}$ guinea-pig lung tissue and chick-embryo yolk-sac membranes, ${ }^{23}$ and primary explanted macrophages from various origins. ${ }^{9,24,25}$ The use of these models to study the pathogenesis of Legionnaires' disease has been of great value.

In guinea-pigs, depletion of circulating PMNL by a course of antipolymorph serum, ${ }^{26,27}$ and subsequent infection with $L$. pneumophila ${ }^{28}$ had the following main effects: it lowered the dose of organisms necessary to establish infection; led to increased numbers of bacteria in the lungs; and 
caused much higher mortality. However, it did not alter the nature or extent of the pulmonary lesions. These results suggest that pathogenic effects are probably caused directly by $L$. pneumophila, in particular by extracellular enzymes such as proteases. ${ }^{29,30}$ Cytopathic changes in tissue-culture monolayers of MRC-5, HeLa, HEp 2 and McCoy cells were demonstrated after inoculation with $L$. pneumophila. $^{21}$

\section{Phagocytosis of $L$. pneumophila by vertebrate phagocytes}

Generally, phagocytosis of micro-organisms appears to follow a common pattern when examined by electronmicroscopy. In this process, phagocyte pseudopods or micropseudopods appear to move circumferentially and more or less symmetrically around the particle being engulfed until their tips meet, fuse and finally enclose the particle within a membrane-bound vacuole. In the case of particles coated with certain IgG or complement components, or both, including red blood cells and lymphocytes, the process occurs as a result of sequential interaction between ligands on the particle surface (Fc portion of $\mathrm{IgG}$ and complement component $\mathrm{C} 3$ ) and specific receptors for these ligands on the phagocytic membrane. ${ }^{31,32}$

Phagocytosis of the Legionnaires' disease bacterium by PMNL occurs by a novel mechanism termed "coiling phagocytosis" in which engulfment of the organism takes place within a pseudopod coil. ${ }^{33}$ Human monocytes, alveolar macrophages and PMNL phagocytose live L. pneumophila by coiling phagocytosis and also phagocytose formalin-, glutaraldehyde- or heat-killed L. pneumophila in the same manner. In contrast, either before or after such treatment, other organisms are phagocytosed by conventional phagocytosis. Monocytes internalise $L$. pneumophila by coiling phagocytosis in the presence or absence of normal human serum. However, treatment of $L$. pneumophila with anti- $L$. pneumophila antiserum of high titre or with both anti-Legionella antiserum of low titre and complement abolishes coiling phagocytosis; these bacteria are internalised by conventional phagocytosis in the presence or absence of complement. The phenomenon of coiling phagocytosis has been shown to be independent of bacterial virulence and it occurred whether or not the bacteria were heatkilled or whether they were pre-opsonised with specific antibody. ${ }^{34}$ The bacterium contains a surface component ( $\mathrm{F}-1$ fraction) of high mol. wt in which resides the serogroup-specific antigen of $L$. pneumophila. Antibody to this fraction is required for phagocytosis of the organism by mammalian phagocytes. $^{35}$

Live $L$. pneumophila induce the formation of a unique type of phagosome that is studded with host-cell ribosomes. Formation of this vacuole entails a complex sequence of cytoplasmic events that takes place during the first $4-8 \mathrm{~h}$ after engulfment and involves host-cell smooth vesicles, mitochondria and ribosomes. ${ }^{36}$ The phagosome does not fuse with the primary or secondary lysosomes of the host cell. This inhibition is partly overcome by coating bacteria with antibody or activating the monocytes. ${ }^{37}$ However, formalinkilled L. pneumophila enter a membrane-bound vacuole around which such cytoplasmic organelles do not occur. ${ }^{36}$ Furthermore, formalin-killed organisms are rapidly degraded within the phagocyte vacuole which does fuse with host-cell granules.

Since both live and formalin-killed L. pneumophila are internalised by coiling rather than conventional phagocytosis, the intracellular fate of the bacterium must be influenced by factors other than those that determine the mode of entry. Live organisms maintain a significantly higher $\mathrm{pH}$ in the phagocytic vacuoles than do formalin-killed organisms. ${ }^{38}$ Ingested intracellular pathogens, including $L$. pneumophila (an obligate, aerobic bacterium that is predominantly a pulmonary pathogen in man) ${ }^{39}$ can resist the antimicrobial systems of phagocytes. Such systems include the reactive oxygen metabolites generated by the phagocytosisinduced respiratory burst and granule constituents released into the phagosome during degranulation. Antimicrobial granule components include the iron-chelating protein lactoferrin, hydrogen peroxide and myeloperoxidase - which have multiple roles in bacterial killing-various acid hydrolases ${ }^{40,41}$ and cationic proteins - which effect very specific lesions on the bacterial surface, resulting in a rapid loss of viability with little overall structural damage. ${ }^{42}$

The mechanism by which $L$. pneumophila resists the antimicrobial activities of the host phagocytes is not known. One possibility is that a specific product of the organism may be involved in the process. L. pneumophila produces: a haemolysin $;{ }^{43}$ several proteases; ${ }^{44,45}$ other exoenzymes $;{ }^{46}$ an endotoxin $;^{47}$ an acid phosphatase, which blocks superoxide-anion production by $\mathrm{PMNL} ;{ }^{48}$ and a (cyto)toxin. ${ }^{49}$

Six discrete extracellular proteases were isolated from L. pneumophila. ${ }^{29}$ When administered into the lungs of guinea-pigs, one protease with in-vitro activity against collagen, casein and gelatin (tissuedestructive protease, TDP) elicited pulmonary 
lesions which were pathogenically similar to those observed in clinical and experimental Legionnaires' disease. ${ }^{29,50}$ Intranasal administration of as little as $20 \mu \mathrm{g}$ of TDP was sufficient to cause death in experimental animals. ${ }^{50}$ Further evidence that $L$. pneumophila protease may play a major role in the pathogenesis of Legionnaires' disease was the demonstration that substantially higher TDP levels occurred in vivo, possibly as a result of induction. ${ }^{30}$ In parallel studies, higher concentrations of lipopolysaccharide (LPS) were detected in supernates of lung-macerates than in culture supernates. The presence of non-cell-associated LPS in maceratesupernate fractions probably indicated the existence of large numbers of dead, lysed organisms. Whilst sonication experiments suggested that cell lysis released very little TDP, ${ }^{51}$ TDP produced by organisms in vivo might account for the higher levels detected in the lungs of infected animals. Another protease, referred to as major secretory protein, is a product of $L$. pneumophila that induces protective cell-mediated immunity in guineapigs. ${ }^{52}$ Characterisation of $L$. pneumophila extracellular protease was further confirmed and extended to show that this protein exhibited proteolytic, cytotoxic and haemolytic activities. ${ }^{53-55}$

L. pneumophila toxin kills several types of tissueculture cells and embryonated hen's eggs. ${ }^{56}$ It is a peptide of $c .1 \cdot 3 \mathrm{Kda}$ that is methanol-soluble, heatstable and sensitive to proteolytic enzymes. ${ }^{49,56}$ It has been observed ${ }^{57}$ that $\mathrm{O}_{2}$ consumption and nicotinamide adenine dinucleotide phosphate (NADPH)-turnover during phagocytosis were impaired in PMNL pre-incubated with L. pneumophila toxin at concentrations that did not affect viability or phagocytosis. In addition, resting and methylene blue-stimulated activities of the hexose-monophosphate shunt were found to be normal in toxintreated PMNL, an observation suggesting that the toxin does not directly affect this pathway's capacity to generate NADPH. Whether or not this toxin contributes to intracellular survival of $L$. pneumophila remains to be determined. Defective triggering of oxidative metabolism in PMNL by $L$. pneumophila toxin has been studied ${ }^{58}$ and it has been shown that the toxin selectively impairs activation of phagocyte superoxide-generating complex without affecting the functional integrity of components of the complex. A recent suggestion ${ }^{59}$ is that live, but not killed, L. pneumophila may contain another cellbound toxin which, at high multiplicities of infection, is capable of causing extensive cytopathic effects on macrophages. Toxicity to macrophages is an important characteristic that may be used to distinguish between virulent and avirulent strains of $L$. pneumophila ${ }^{59}$ phagocytosis appears to be necessary for cytotoxicity because incubation at $4^{\circ} \mathrm{C}$ or addition of cytochalasin-D, each of which inhibit engulfment of cells, inhibits toxic activity.

\section{Comparison of virulent and avirulent $L$. pneumophila}

Intracellular survival of the Legionnaires' disease bacterium is dependent on the virulence of the organism. ${ }^{60}$ Virulent organisms multiplied very rapidly in lungs of guinea-pigs, reaching a concentration of $5 \times 10^{11}$ viable organisms/lung. Bacteria were present in the blood, liver, spleen and kidney. On the other hand, an avirulent strain was unable to replicate after inoculation into the lungs and was not found in any other organs. About 10 times more viable bacteria were recovered from lung macrophages than from lung PMNL when infected with virulent $L$. pneumophila; but similar numbers of bacteria were recovered from both cell types when avirulent strains were employed.

Agar-adapted L. pneumophila lose their virulence for chicken embryos and guinea-pigs ${ }^{61}$ and repeated passage of virulent $L$. pneumophila cultures on supplemented Mueller-Hinton (SMH) agar has been widely accepted as a method for obtaining avirulent derivative cultures. When these avirulent cultures are passaged through living hosts, including guinea-pigs, virulent cultures have been recovered. ${ }^{62,63}$ In most studies on virulence conversion of $L$. pneumophila, liquid batch cultures which may contain a mixture of virulent and avirulent populations have been used. However, Catrenich and Johnson ${ }^{64}$ selected isolated colonies derived from liquid batch cultures and showed that virulence conversion was a one-way phenomenon, i.e., from virulent to avirulent. The only occasion in which virulent $L$. pneumophila was recovered from an avirulent culture was when the avirulent culture was derived from a saline suspension of a virulent culture which had been passaged only five times on SMH; but when an avirulent culture was derived from a virulent culture passaged 25 times on SMH agar, virulent cultures were not recovered even after successive passage through guinea-pigs. SMH agar appears to act as a selective medium for the growth of avirulent organisms. It is possible that virulent $L$. pneumophila cells are unable to grow on SMH agar but remain viable for several SMHagar passages and can be recovered subsequently on charcoal yeast-extract agar. This would explain the observation by fluorescence microscopy of viable, but non-cultivable, L. pneumophila in environmental-water samples plated on SMH. ${ }^{65}$ 
Virulent strains are phagocytosed and replicate within phagocytic cells; avirulent strains appear to resist phagocytosis and when they are phagocytosed, do not replicate within phagocytic cells. ${ }^{66}$ After phagocytosis, avirulent strains are more efficiently killed intracellularly than virulent strains. Both kinds of strains enter phagocytes by coiling phagocytosis; thereafter, their intracellular destinies diverge. The virulent organisms form a distinctive ribosome-lined replicative phagosome and inhibit phagosome fusion; the avirulent strain neither forms a distinctive phagosome nor inhibits phagosome-lysosome fusion. ${ }^{33,66}$

When PMNL were challenged with avirulent strains of $L$. pneumophila, they produced more chemiluminescence and superoxide anion than those challenged by virulent strains. ${ }^{67}$ This phenomenon may be due either to active suppression of PMNL responses by virulent strains or to varying degrees of opsonisation. A cytotoxin of low mol. wt has been isolated ${ }^{58}$ from L. pneumophila that altered PMNL-oxidative metabolism; more recently, the blockage of superoxide-anion production in human PMNL by the activity of an acid phosphatase isolated from $L$. micdade $i$ has been described. ${ }^{48}$ However, differences in the production of these substances by virulent and avirulent strains have not been reported. The extent of opsonisation may also be related to virulence. Avirulent strains generally bind more $\mathrm{C} 3$ than virulent strains, except that one virulent strain (Lou 1v) bound considerably more C3 than its avirulent variant (Lou 1). The reversed pattern of $\mathrm{C} 3$ binding by Lou 1 and Lou $1 \mathrm{v}$ variants (avirulent and virulent respectively) suggests that phagocytic-cell responses to $L$. pneumophila may be altered by other unidentified virulenceassociated factors. ${ }^{67}$ The differences observed in chemiluminescence are not completely understood. One possibility is that measurement of chemiluminescence in PMNL may involve the detection of other oxygen radicals, even though the lucigeninassay system used ${ }^{67}$ is reported to be specific for detection of superoxide radicals. ${ }^{68}$

Virulent strains of $L$. pneumophila are cytotoxic for alveolar macrophages when added at a multiplicity of infection of $100 \mathrm{~L}$. pneumophila per macrophage. Under the same conditions, avirulent strains exhibit little cytotoxic activity. ${ }^{59}$ Virulent, but not avirulent, strains were resistant to bactericidal activity when incubated in the presence of normal human serum $(10 \%$ or $50 \%)$ and failed to bind complement components (C3 and C9). The mechanism of serum resistance of virulent strains of $L$. pneumophila is not known. In other organisms, complement activation and deposition are associ- ated with LPS and outer-membrane proteins. Although studies of the composition of LPS from virulent strains of $L$. pneumophila have been published recently, ${ }^{69}$ little is known about differences in the composition and structure of LPS isolated from virulent and avirulent strains. It has been reported ${ }^{66}$ that a virulent strain of $L$. pneumophila and its avirulent variant had similar structural and secretory protein and LPS. However, more recently, Keevil et al. (personal communication) found a decrease in the LPS constituents and the virulence of $L$. pneumophila grown in continuous culture under nutrient-limited conditions.

Virulent strains of $L$. pneumophila grown in the human macrophage-like cell line ${ }^{12}$ induce a cytopathic effect in these cells. In contrast, avirulent strains neither multiply in this cell line nor produce a cytopathic effect. Therefore, this cell line was able to differentiate between virulent and avirulent strains of $L$. pneumophila. Furthermore, several other systems have been used to assay virulence of Legionella. These include guinea-pigs, ${ }^{70}$ amoebae, ${ }^{17}$ and virus-like plaque formation in mouse L929 cells. $^{71}$ All these techniques are difficult to perform and can not be used routinely in clinical laboratories. Recently, Halablab et al. ${ }^{72}$ reported a simple technique for differentiating virulent from avirulent $L$. pneumophila based on the ability of viable $L$. pneumophila to reduce nitroblue-tetrazolium to an insoluble formazan in the presence of either Acanthamoeba polyphaga or human PMNL. On microscopic examination, deposits of formazan around Legionella cells may be observed inside amoebae similar to those inside human neutrophils (Halablab, unpublished observations).

\section{L. pneumophila and protozoa}

Among amoeboid protozoa, phagocytosis is not only the means of defence against foreign cells and particles ${ }^{73}$ but also the principal mode of ingesting food. Sponges, molluscs, annelids, arthropods, echinoderms and tunicates also use ingestion by phagocytic cells to dispose of unwanted cells and particles. Their phagocytes and other related cells can also combine to encapsulate and isolate invading particles or organisms that are too large to be engulfed by a single cell. ${ }^{73-76}$

Free-living amoebae of the genera Naegleria and Acanthamoeba are ubiquitous in soil and water. The commonest species, $A$. polyphaga, $A$. castelanii and $N$. gruberi, have been isolated from humidifiers and may be present in such environments in large numbers. Amoebae and $L$. pneumophila were detected in $38-88 \%$ of ground, drinking or whirlpool 
waters tested. ${ }^{77}$ Amoebae isolated from river water were found to contain legionellae. ${ }^{78}$ Rowbotham $^{20}$ was the first to report phagocytosis of $L$. pneumophila by amoebae and suggested that a vacuole, or an amoeba, full of legionellae might be the infective particle for man rather than free legionellae themselves. However, when L. pneumophila was inoculated into axenic cultures of $N$. lovaniensis and $A$. royreba, $99.9 \%$ of the bacteria were destroyed within 24 h. ${ }^{79}$ After several weeks, however, some amoeba cultures became chronically infected and supported the intracellular growth of $L$. pneumophila. Amoebae exposed to L. pneumophila and containing adherent L pneumophila, L. pneumophila antigens, or both, showed no increased pathogenic potential on intranasal inoculation of weaning mice. Similarly, L. pneumophila propagated in chronically infected amoeba cultures showed no increase in virulence on intraperitoneal inoculation of guinea-pigs in comparison with L pneumophila grown in yeast-extract broth. Since the bacteria did not grow in the media designed for the amoebae, the amoebae provided either an intracellular niche or extracellular factors that supported the growth of $L$. pneumophila. However, viable counts of $L$. pneumophila declined rapidly either in amoeba culture medium alone or when bacteria and amoebae were separated by a microporous membrane. ${ }^{15}$ Therefore, direct amoeba-legionella contact is required for this growth. Furthermore, numerous bacteria, including some dividing forms, were observed within vacuoles in the cytoplasm. These results differ from those obtained with cyanobacteria plus Legionella cultures in which the latter requires extracellular growth factors from the former. ${ }^{80}$

As mentioned above, Legionella cells phagocytosed by mammalian phagocytic cells are enclosed in vacuoles which are enriched by one or more mitochondria apposed to the vacuolar membrane. Subsequently, ribosomes line the margin of the bacteria-filled vacuole. ${ }^{36}$ The same sequence of cytoplasmic events took place when $L$. pneumophila was phagocytosed by $N$. fowleri. ${ }^{16}$ In amoebal saline alone, destruction of legionellae was apparent and the bacteria did not multiply. However, in amoebaculture medium the number of bacteria increased, suggesting that amoebae require nutritionally replete conditions, and perhaps additional factors, to promote an increase in Legionella cell numbers.

An ecological model has been established that has led to the development of an enrichment method for Legionella. ${ }^{81}$ Cells of the ciliate protozoan, Tetrahymena pyriformis, were infected with 1-30 L. pneumophila cells in sterile tap water at $35^{\circ} \mathrm{C}$. Seven days after inoculation, serpentine chains of $c .10^{3}$ L. pneumophila were observed throughout the cytoplasm of the protozoan. $L$. pneumophila did not multiply in sterile tap water alone, in suspensions of lysed $T$. pyriformis or in cell-free filtrates of a $T$. pyriformis culture. Evaluation of 17 strains of $L$. pneumophila for virulence by intraperitoneal injection of guinea-pigs and inoculation into cultures of $T$. pyriformis showed that, with respect to virulence, there are four categories of legionellae ${ }^{17}$ : (1) organisms that infect and kill guinea-pigs and multiply in $T$. pyriformis; (2) organisms that infect but do not kill guinea-pigs and multiply in $T$. pyriformis; (3) organisms that do not infect guinea-pigs but are lethal at high concentration and multiply in $T$. pyriformis; and (4) organisms that neither infect nor kill guinea-pigs and fail to multiply in $T$. pyriformis. The existence of category-2 strains suggests that intracellular multiplication is not the only factor responsible for the clinical manifestations of infection with Legionella species in guinea-pigs; toxic activity may also be involved. Any Legionella isolate which produces death or illness in the guinea-pig or multiplies intracellularly in $T$. pyriformis should be considered pathogenic for man.

Rowbotham $^{82}$ developed an amoebal enrichment method for the isolation and amplification of viable legionellae from clinical materials. Studies on these L. pneumophila isolates led to the discovery that virulent legionellae are attracted to suitable host amoebae, possibly by chemotaxis, indicating that infection does not result from random collision.

The pathogenicity of some strains of amoebae belonging to the genera Naegleria and Acantham$o e b a$ is directly related to temperature. ${ }^{83}$ The interaction between L. pneumophila and Acantham$o e b a$ also seems to be temperature dependent. ${ }^{19}$ When $L$. pneumophila was cultured with $A$. palestinensis at $35^{\circ} \mathrm{C}$, the bacterial population that developed was significantly greater than that obtained at lower temperatures and some bacteria were seen to be expelled from phagosomes. Furthermore, in some amoebae, the cytoplasm was full of bacteria and in others the process of encystment commenced. At $20^{\circ} \mathrm{C}$, A.palestinensis phagocytosed and digested legionellae. Although the bacteria disappeared after the second day of co-culture, legionellae re-appeared in low numbers by the sixth day suggesting that even at this temperature some intra-amoebal multiplication occurred. Similar events were described by other workers ${ }^{79}$ who did not mention, however, experimental temperature. The formation of thick-walled amoebal structures (amoebal cysts) may enable intracellular packets of 
legionellae to survive more adverse conditions than free bacteria or bacteria in vegetative amoebae. ${ }^{19}$

The implications of intra-amoebal growth of $L$. pneumophila are significant. Not only are acanthamoebae able to promote growth of Legionella, as are the cyanobacteria, ${ }^{84}$ but the intracellular locus of this growth may well contribute to the difficulty encountered in removing Legionella from cooling towers and similar environments by routine maintenance procedures. ${ }^{85}$ As shown elsewhere, ${ }^{86}$ legionellae may be observed within Acanthamoeba cysts under experimental conditions. If $L$. pneumophila can survive the differentiation of acanthamoebae into the cyst form, intracellular residence might provide even greater protection for longer periods because of the unusual stability of such cysts to treatment such as hyperchlorination. ${ }^{87}$ If this resistance applied equally to the thick-walled amoebae containing $L$. pneumophila, it would explain how the organism is seeded into domestic piped-water supplies from which legionellae are commonly isolated. In addition, infected amoebae might provide a reservoir for survival of legionellae when conditions, such as temperature and light intensity, become unfavourable for growth of other supporting organisms such as cyanobacteria.

\section{Concluding comments}

Legionellae are ubiquitous in the environment, occurring in low numbers in both natural and manmade bodies of water. Although they cannot grow in pure culture in these environments, they reproduce successfully when other naturally occurring species are present. This ability may arise from the provision of essential growth factors, either extracellularly (in the case of cyanobacteria) or intracellularly (in amoebae) and in the latter case is a consequence of the organism's ability to resist the digestive processes of the host cell. That kind of resistance may be a factor in the dispersal of legionellae to domestic water supplies and may also be important in droplet infection of man.

Within the infected lung, legionellae are taken up into phagocytic cells by an unusual mechanism and virulent strains resist their antimicrobial

\section{REFERENCES}

1. Metschnikoff E. Untersuchungen uber die mesodermalen Phagocyten einiger Wirbeltiere. Biol Centralbl 1884; 3 : 560-565.

2. Bellanti JA. Mechanism of immunity to bacterial disease.

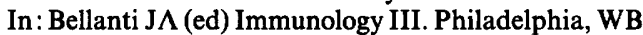
Saunders Co. 1985: 272-282. systems. The similarity between this resistance plus intracellular multiplication in phagocytes and that in amoebae is very striking and may result from a common mechanism. Virulent $L$. pneumophila produce a variety of substances which are toxic to human cells and influence the course of disease. The intracellular site of $L$. pneumophila may also afford some protection against therapeutic agents.

Although knowledge of the legionellae and their interaction with other cells has increased considerably in recent years, several important questions remain to be answered. It is likely that the successful control of Legionnaires' disease and its milder relative, Pontiac fever, will require answers to some or all of these questions. In particular, we may enquire further into the similarity described above and the likely questions may include: What are the surface characteristics of Legionella cells that prompt phagocytosis to occur by coiling in human cells and is there any similar characteristic associated with ingestion by amoebae? What (if any) are the similarities between the phagocyte and the amoebal surface responsible for the recognition of Legionella? How is the shift in legionellae-amoebae interaction occasioned by altering the incubation temperature brought about? How similar are the intracellular events in amoebae and phagocytes, do any events analogous to those in the replicative phagosome occur in amoebae and is lysosomephagosome fusion inhibited in amoebae as in mammalian cells? Do the virulence factors possessed by pathogenic strains of Legionella have any effect on the amoeba-legionella interaction? Do legionellae produce the toxins and proteases described above intra-amoebally and, if so, how do amoebae resist them? What essential growth factors are legionellae receiving from co-cultured organisms and do they require similar factors within the legionella-phagocyte interaction?

We conclude by expressing the hope that future research may look more closely into some of these questions and that the answers will prove to be of value in the prevention and cure of Legionnaires' disease.

We thank the Hariri Foundation for financial support to one of us (MAH) and Dr R. Miles for helpful advice.

3. Fallon RJ. Epidemiological and microbiological aspects of an outbreak of Pontiac Fever. J Appl Bacteriol 1989; 67: viii.

4. Nagington J, Smith DJ. Pontiac fever and amoebae. Lancet $1980 ; 2: 1241$.

5. Horwitz MA, Silverstein SC. Legionnaires' disease bacterium (Legionella pneumophila) multiplies intracellularly in human monocytes. $J$ Clin Invest $1980 ; 66$ : 441-450. 
6. Chandler FW, Hicklin MD, Blackmon JA. Demonstration of the agent of Legionnaires' disease in tissue. $N$ Engl J Med 1977; 297: 1218-1220.

7. Blackmon JA, Chandler FW, Hicklin MD. Pathologic features of Legionnaires' disease. In : Jones GL, Herbert GA (eds) Legionnaires: The disease, the bacterium and methodology. U.S. Department of Health, Education, and Welfare, Public Health Service, Center for Disease Control, Bureau of Laboratories, Atlanta, GA, Publication No. (CDC) 79-8375 1978; 9-11.

8. Chandler FW, McDade JE, Hicklin MD, Blackmon JA, Thomason BM, Ewing EP. Pathologic findings in guinea pigs inoculated intraperitoneally with the Legionnaires' disease bacterium. Ann Intern Med 1979; 90: 671-675.

9. Kishimoto RA, Kastello $\mathrm{MD}$, White JD et al. In vitro interaction between normal cynomolgus monkey alveolar macrophages and Legionnaires' disease bacteria. Infect Immun 1979; 25 : 761-763.

10. Davis GS, Winn WC, Gump DW, Craighead JE, Beaty $\mathbf{H}$ $\mathrm{N}$. Legionnaires' pneumonia after aerosol exposure in guinea pigs and rats. Am Rev Respir Dis 1982; 126: 1050-1057.

11. Katz SM, Hashemi S. Electron microscopic examination of the inflammatory response to Legionella pneumophila in guinea pigs. Lab Invest 1982; 46: 24-32.

12. Pearlman E, Jiwa AH, Engleberg NC, Eisenstein BI. Growth of Legionella pneumophila in a human macrophage-like (U937) cell line. Microb Pathog 1988; 5 : 87 95.

13. Cianciotto NP, Eisenstein BI, Mody $\mathrm{CH}$, Toews GB, Engleberg NC. A Legionella pneumophila gene encoding a species-specific surface protein potentiates initiation of intracellular infection. Infect Immun 1989; 57: 1255 1262.

14. Engleberg NC, Carter C, Weber DR, Cianciotto NP, Eisenstein BI. DNA sequence of mip, a Legionella pneumophila gene associated with macrophage infectivity. Infect Immun 1989; 57: 1263-1270.

15. Holden EP, Winkler HH, Wood DO, Leinbach ED. Intracellular growth of Legionella pneumophila within Acanthamoeba castellanii Neff. Infect Immun 1984; 45 : 18-24.

16. Newsome AL, Baker RL, Miller RD, Arnold RR. Interactions between Naegleria fowleri and Legionella pneumophila. Infect Immun 1985; 50 : 449-452.

17. Fields BS, Barbaree JM, Shotts EB et al. Comparison of guinea pig and protozoan models for determining virulence of Legionella species. Infect Immun 1986; 53: 553-559.

18. Fields BS, Sanden GN, Barbaree JM et al. Intracellular multiplication of Legionella pneumophila in amoebae isolated from hospital hot water tanks. Curr Microbiol $1989 ; 18$ : 131-137.

19. Anand CM, Skinner AR, Malic A, Kurtz JB. Interaction of Legionella pneumophila and a free living amoeba (Acanthamoeba palestinensis). J Hyg (Lond) 1983; 91 : 167-178.

20. Rowbotham TJ. Preliminary report on the pathogenicity of Legionella pneumophila for freshwater and soil amoebae. $J$ Clin Pathol 1980; 33: 1179-1183.

21. Daisy JA, Benson CE, McKitrick J, Friedman HM. Intracellular replication of Legionella pneumophila. $J$ Infect Dis $1981 ; 143: 460-464$.

22. Oldham LJ, Rodgers FG. Adhesion, penetration and intracellular replication of Legionella pneumophila: an in vitro model of pathogenesis. $J$ Gen Microbiol 1985; 131 : 697-706.

23. Surgot M, Barioz CM, Nowicki M, Bornstein N, Fleurette J. An electron microscopy study of Legionella pneumophila after in vitro and in vivo culture. Zentralbl Bakteriol Mikrobiol Hyg 1988; 269A: 26-33.

24. Kishimoto RA, White J D, Shirey FG et al. In vitro response of guinea pig peritoneal macrophages to Legionella pneumophila. Infect Immun 1981; 31 : 1209-1213.

25. Yamamoto Y, Klein TW, Newton CA, Widen R, Friedman $\mathrm{H}$. Growth of Legionella pneumophila in thioglycolateelicited peritoneal macrophages from $\mathbf{A} / \mathbf{J}$ mice. Infect Immun 1988; 56: 370-375.

26. Simpson DM, Ross R. Effect of heterologous antineutrophil serum in guinea pigs. Haematologic and ultrastructural observations. Am J Pathol 1971 ; 65: 79-102.

27. Simpson DM, Ross R. The neutrophilic leukocyte in wound repair, a study with antineutrophil serum. $J$ Clin Invest $1972 ; 51$ : 2009-2023.

28. Fitzgeorge RB, Featherstone ASR, Baskerville A. Effects of polymorphonuclear leucocyte depletion on the pathogenesis of experimental Legionnaires' disease. Br J Exp Pathol 1988; 69: 105-112.

29. Conlan JW, Baskerville A, Ashworth LAE. Separation of Legionella pneumophila proteases and purification of a protease which produces lesions like those of Legionnaires' disease in guinea-pig lung. J Gen Microbiol 1986; 132: $1565-1574$.

30. Conlan JW, Williams A, Ashworth LAE. In vivo production of a tissue-destructive protease by Legionella pneumophila in the lungs of experimentally infected guinea pigs. J Gen Microbiol 1988; 134: 143-149.

31. Griffin FM, Griffin JA, Leider JE, Silverstein SC. Studies on the mechanism of phagocytosis. I. Requirements for circumferential attachment of particle-bound ligands to specific receptors on the macrophage plasma membrane. J Exp Med 1975; 142: 1263-1282.

32. Griffin FM, Griffin JA, Silverstein SC. Studies on the mechanism of phagocytosis. II. The interaction of macrophages with anti-immunoglobulin IgG-coated bone marrow-derived lymphocytes. J Exp Med 1976; 144: 788-809.

33. Horwitz MA. Phagocytosis of Legionnaires' disease bacterium (Legionella pneumophila) occurs by a novel mechanism: engulfment within a pseudopod coil. Cell 1984; 36: $27-33$

34. Rechnitzer C, Blom J. Engulfment of Philadelphia strain of Legionella pneumophila within pseudopod coils in human phagocytes. Comparison with other Legionella strains and species. APMIS 1989; 97: 105-114.

35. Johnson W, Pesanti E. Elliott J. Serospecificity and opsonic activity of antisera to Legionella pneumophila. Infect Immun 1979; 26: 698-704.

36. Horwitz MA. Formation of a novel phagosome by the Legionnaires' disease bacterium (Legionella pneumophila) in human monocytes. J Exp Med 1983; 158: 1319-1331.

37. Horwitz MA. The Legionnaires' disease bacterium (Legionella pneumophila) inhibits phagosome-lysosome fusion in human monocytes. J Exp Med 1983; 158: 21082126.

38. Horwitz MA, Maxfield FR. Legionella pneumophila inhibits acidification of its phagosome in human monocytes. $J$ Cell Biol 1984; 99: 1936-1943.

39. McDade JE, Shepard CC, Fraser DW, Tsai TR, Redus MA, Dowdle WR. Legionnaires' disease: isolation of a bacterium and demonstration of its role in other 
respiratory disease. $N$ Eng $J$ Med 1977; 297: 11971203.

40. Klebanoff SJ, Clark RA. The neutrophil: function and clinical disorders. Amsterdam, New York \& Oxford, North-Holland Publishing Co. 1978.

41. Klebanoff SJ. Oxygen-dependent cytotoxic mechanisms of phagocytes. In: Gallin JI, Fauci AS (eds) Advances in host defense mechanisms, vol. 1 ; Phagocytic cells. New York, Raven Press. 1982: 111.

42. Weiss J, Stendahl O, Elsbach $\mathbf{P} . \mathrm{O}_{2}$-independent killing of gram-negative bacteria by intact granulocytes. The role of a potent bactericidal membrane-perturbing protein. In : Rossi F, Patriarca P (eds) Biochemistry and function of phagocytes. Advances in Experimental Medicine and Biology, vol. 141. New York, Plenum. 1982: 129137.

43. Baine WB, Rasheed JK, Mackel DC, Bopp CA, Wells J G, Kaufmann A F. Exotoxin activity associated with the Legionnaires' disease bacterium. J Clin Microbiol 1979; 9: 453-456.

44. Muller HE. Proteolytic action of Legionella pneumophila on human serum proteins. Infect Immun 1980; 27: 51-53.

45. Thompson R, Miller RD, Iglewski BH. In vitro production of an extracellular protease by Legionella pneumophila. Infect Immun 1981; 34: 299-302.

46. Thorpe TC, Miller RD. Extracellular enzymes of Legionella pneumophila. Infect Immun 1981; 33: 632-635.

47. Wong KH, Moss CW, Hochstein DH, Arko RJ, Schalla WO. "Endotoxicity" of the Legionnaires' disease bacterium. Ann Intern Med 1979; 90: 624-627.

48. Saha AK, Dowling JN, LaMarco KL et al. Properties of an acid phosphatase from Legionella micdadei which blocks superoxide anion production by human neutrophils. Arch Biochem Biophys 1985; 243: 150-160.

49. Friedman RL, Iglewski BH, Miller RD. Identification of a cytotoxin produced by Legionella pneumophila. Infect Immun 1980; 29: 271-274.

50. Baskerville A, Conlan JW, Ashworth LAE, Dowsett AB. Pulmonary damage caused by a protease from Legionella pneumophila. Br J Exp Pathol 1986; 67: 527-536.

51. Berdal BP, Olsvik O, Myhre S, Omland T. Demonstration of extracellular chymotrypsin-like activity from various Legionella species. J Clin Microbiol 1982; 16: 452- 457.

52. Blander SJ, Horwitz MA. Vaccination with the major secretory protein of Legionella pneumophila induces cellmediated and protective immunity in a guinea pig model of Legionnaires' disease. J Exp Med 1989; 169: 691-705.

53. Keen MG, Hoffman PS. Characterization of Legionella pneumophila extracellular protease exhibiting hemolytic and cytotoxic activities. Infect Immun 1989; 57: 732738.

54. Quinn FD, Keen MG, Tompkins LS. Genetic, immunological and cytotoxic comparisons of Legionella proteolytic activities. Infect Immun 1989; 57: 2719-2725.

55. Quinn FD, Tompkins LS. Analysis of a cloned sequence of Legionella pneumophila encoding a $38 \mathrm{kD}$ metalloprotease possessing haemolytic and cytotoxic activities. Mol Microbiol 1989; 3: 797-805.

56. Friedman RL. A novel toxin produced by Legionella pneumophila. Washington, DC, American Society of Microbiology. 1981 ; abstract no. B26, p. 19.

57. Friedman RL, Lochner JE, Bigley RH, Iglewski BH. The effects of Legionella pneumophila toxin on oxidative processes and bacterial killing of human polymorphonuclear leucocytes. J Infect Dis 1982; 146: 328-334.

58. Lochner JE, Bigley RH, Iglewski BH. Defective triggering of polymorphonuclear leucocyte oxidative metabolism by Legionella pneumophila toxin. J Infect Dis 1985; 151 : $42-46$.

59. Caparon M, Johnson W. Macrophage toxicity and complement sensitivity of virulent and avirulent strains of Legionella pneumophila. Rev Infect Dis 1988; 10 Suppl 2: S377-S381.

60. Jepras RI, Fitzgeorge RB, Baskerville A. A comparison of virulence of two strains of Legionella pneumophila based on experimental aerosol infection of guinea pigs. $J \mathbf{H y g}$ $1985 ; 95: 29-38$.

61. McDade JE, Shepard CC. Virulent to avirulent conversion of Legionnaires' disease bacterium (Legionella pneumophila)-its effect on isolation techniques. $J$ Infect Dis $1979 ; 139$ : 707-711.

62. Elliott JA, Johnson W. Virulence conversion of Legionella pneumophila serogroup 1 by passage in guinea pigs and embryonated eggs. Infect Immun 1982; 35: 943-946.

63. Wong MC, Peacock WL, McKinney RM, Wong $\mathrm{KH}$. Legionella pneumophila : avirulent to virulent conversion through passage in cultured human embryonic lung fibroblasts. Curr Microbiol 1981 ; 5: 31-34.

64. Catrenich CE, Johnson W. Virulence conversion of Legionella pneumophila: A one-way phenomenon. Infect Immun 1988; 56: 3121-3125.

65. Hussong D, Colwell RR, O'Brien M et al. Viable Legionella pneumophila not detectable by culture on agar media. Bio/Tech 1987; 5: 947-950.

66. Horwitz M A. Characterization of avirulent mutant Legionella pneumophila that survive but do not multiply within human monocytes. $J$ Exp Med 1987; 166: 13101328.

67. Summersgill JT, Raff MJ, Miller RD. Interactions of virulent and avirulent Legionella pneumophila with human polymorphonuclear leukocyte. Microb Pathog $1988 ; 5: 41-47$.

68. Allen RC. Lucigenin-chemiluminescence: new approach to the study of polymorphonuclear leucocyte redox activity. In: DeLuca MA, McElroy WD (eds) Bioluminescence and chemiluminescence. New York, Academic Press. 1981: 63-73.

69. Otten S, Iyer S, Johnson W, Montgomery R. Serospecific antigens of Legionella pneumophila. J Bacteriol 1986; 167: 893-904.

70. Baskerville A, Fitzgeorge RB, Broster M, Hambleton P, Dennis PJ. Experimental transmission of legionnaires' disease by exposure to aerosols of Legionella pneumophila. Lancet 1981 ; 2: 1389-1390.

71. Fernandez RC, Lee SHS, Haldane D, Sumarah R, Rozee K R. Plaque assay for virulent Legionella pneumophila. $J$ Clin Microbiol 1989; 27: 1961-1964.

72. Halablab MA, Bazin M, Richards L. Estimation of Legionella pneumophila virulence by nitroblue-tetrazolium reduction. Lancet 1990; 335: 240.

73. Manning MJ, Turner RJ. Comparative immunobiology. New York, Halsted/Wiley, 1976.

74. Cooper EL. Comparative immunology. Englewood Cliffs, NJ, Prentice-Hall, 1976.

75. Cohen N, Sigel MM (eds) The reticuloendothelial system : a comprehensive treatise; vol 3, Phylogeny and ontogeny. New York, Plenum. 1982.

76. Salt G. The cellular defense reactions of insects. London, Cambridge University Press. 1970.

77. Henke M, Seidel KM. Association between Legionella pneumophila and amoebae in water. Isr J Med Sci 1986; 22: 690-695.

78. Harf C, Monteil H, Vetter MT. Relations amibes libres 
Legionella dans l'environnement. Colloque Legionella. Lyon, Faculte de Medecine Alexis Carrel. 1987.

79. Tyndall RL, Domingue EL. Cocultivation of Legionella pneumophila and free-living amoebae. Appl Environ Microbiol 1982; 44: 954-959.

80. Tison DL, Pope DH, Cherry WB, Fliermans CB. Growth of Legionella pneumophila in association with blue-green algae (Cyanobacteria). Appl Environ Microbiol 1980; 39: 456-459.

81. Fields BS, Shotts EB, Feeley JC, Gorman GW, Martin W T. Proliferation of Legionella pneumophila as an intracellular parasite of the ciliated protozoan Tetrahymena pyriformis. Appl Environ Microbiol 1984; 47: 467-471.

82. Rowbotham TJ. Isolation of Legionella pneumophila from clinical specimens via amoebae, and the interaction of those and other isolates with amoebae. $J$ Clin Pathol $1983 ; 36$ : 978-986.

83. Griffin JL. Temperature tolerance of pathogenic and non pathogenic free-living amoebas. Science 1972; 178: 869-870.

84. Pope DH, Soracco RJ, Gill HK, Fliermans CB. Growth of Legionella pneumophila in two-membered cultures with green algae and cyanobacteria. Curr Microbiol 1982; 7: 319-321.

85. England AC, Fraser DW, Mallison GF, Mackel DC, Skaliy P, Gorman GW. Failure of Legionella pneumophila sensitivities to predict culture results from disinfectanttreated air-conditioning cooling towers. Appl Environ Microbiol 1982; 43: 240-244.

86. Skinner AR, Anand CM, Malic A, Kurtz JB. Acanthamoebae and environmental spread of Legionella pneumophila. Lancet 1983; 2: 289-290.

87. de Jonckheere J, van de Voorde H. Differences in destruction of cysts of pathogenic and nonpathogenic Naegleria and Acanthamoeba by chlorine. Appl Environ Microbiol $1976 ; 31: 294-297$. 